\title{
POR UMA EXPERIÊNCIA SEM ADJETIVOS ${ }^{1}$
}

Camila de Castro Castilho ${ }^{2}$

\section{PARA ONDE VAI ESSA ESTRADA?}

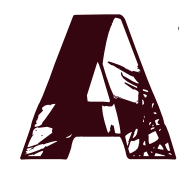

trajetória desta experiência não tem início em maio de 2013, quando corri loucamente para renovar meu passaporte e Ministério da Educação e ao Ministério das Relações Internacionais e enviá-los para a Espanha. Ela também data de antes do evento do Conversas ao Pé da Página, de 2011, ano da primeira edição do seminário coordenado pela A Cor da Letra e pela Revista Emília que, dois anos mais tarde, faria com que eu entrasse em contato com Dolores Prades, publisher da Revista Emília e professora convidada do curso de "Libros y Literatura Infantil y Juvenil ${ }^{3 ",}$ da Universitat Autònoma Barcelona, que foi quem escreveu a carta à Universidade, recomendando-me como futura aluna do curso.

Minha relação acadêmica com os livros e com a literatura infantil e juvenil começa em 2003, quando eu era graduanda de Letras na Faculdade de Filosofia, Letras e Ciências Humanas da Universidade de São Paulo. Na época, as optativas com o nome de Literatura Infantil e Juvenil: Linguagens do Imaginário chamaram minha atenção e eu decidi que tinha que fazer todas as quatro disciplinas oferecidas. Esta decisão direcionou não apenas meu caminho acadêmico, mas, também, profissional.

10 título escolhido para o presente diário acadêmico faz menção ao título do livro "Por uma literatura sem adjetivos", de María Teresa Andruetto, traduzido por Carmem Cacciacarro, publicado no Brasil pela editora Pulo do Gato, que apresenta ensaios e reflexões sobre literatura, sobretudo aquela "destinada" a crianças e jovens e propõe questionamentos sobre o por quê e a necessidade de haver distinções, separações e funções tão demarcadas.

2 Camila de Castro Castilho (ou Camila Castro) é formada em Letras pela USP, pós-graduada em Jornalismo pela Cásper Líbero, especialista em Livros e Literatura Infantil e Juvenil pela Univesitat Autònoma de Barcelona e mestranda em Linguística Aplicada pela Unicamp. É coordenadora de conteúdo e design educacional, mas já trabalhou como editora e formadora de mediadores de leitura.

3 Livros e Literatura Infantil e Juvenil (tradução nossa). 
Formada, trabalhei durante dois anos em uma grande livraria de São Paulo, no setor infantil, onde conheci o outro lado dos livros, o comercial, e um lado da literatura que não havia aprendido (o das editoras). Minha trajetória profissional seguiu a linha dos livros e da literatura: fui trabalhar implantando bibliotecas e formando mediadores de leitura. E, embora tivesse feito pós-graduação em jornalismo e estudado a literatura juvenil como espetáculo, em 2008, sentia falta de embasamentos e discussões teóricas.

Entretanto, quem trabalha com dedicação exclusiva em regime de CLT 40-44 horas sabe que é praticamente impossível dedicar-se a uma formação contínua acadêmica, sobretudo em uma universidade pública, onde os cursos são dados no horário de trabalho.

Encontrei na proposta do Máster ${ }^{4}$ em Libros y Literatura Infantil y Juvenil, do Departamento de Didática de Língua, Literatura e Ciência Sociais, da Faculdade de Ciências da Educação da Universitat Autònoma Barcelona, a alternativa que precisava porque ele oferece para os alunos que são de outros países as opções de frequentar o curso de forma semipresencial ou, até mesmo, inteiramente on-line.

\section{BARCELONA: DE LONGE, DE PERTO, DE LONGE}

A primeira vez que entrei em contato com a proposta do mestrado da Universitat Autònoma Barcelona foi em 2012, por intermédio da então coordenadora de Língua Portuguesa do Ensino Fundamental II da Escola da Vila, Aline Evangelista Martins. A princípio, minha crítica residia no fato de os referenciais teóricos serem diferentes e distantes dos que eu tinha, mas, aos poucos, identifiquei este fato como uma possibilidade de troca e aprendizado.

Um ano depois, em 2013, estava realizando um curso no Instituto Emília - e já estava em contato com estes referencias teóricos. Foi

4 Mestrado (tradução nossa). 
quando surgiu a oportunidade, inclusive financeira, de realizar o curso. O que não está discriminado nos sites das universidades estrangeiras que oferecem a possibilidade de uma formação acadêmica ou mesmo um curso livre semipresencial e on-line para estrangeiros é a importância e a quantidade de documentação e seus respectivos prazos de entrega.

Comecei, em abril de 2013, a correr atrás da documentação que deveria ficar pronta até o início de agosto, para começar as aulas em setembro, que é o início do ano letivo nos países europeus. Ainda assim, quando a $7^{a}$ edición do Máster começou, meu passaporte não tinha ficado pronto e perdi a aula inaugural. Mas pude assistir on-line Teresa Colomer $^{5}$, Coordenadora do Grupo de Pesquisa de Literatura Infantil e Juvenil e de Educação Literária $\left(G_{\text {retel }}^{6}\right)$, iniciar o curso. Os alunos mandaram fotos deste dia e de quem estava lá para a aula inaugural (tanto dos alunos que fariam o curso presencial como daqueles que estavam apenas para a aula inaugural, mas que fariam o curso semipresencial):

5 Doutora em Ciências da Educação e coordenadora do Grupo de Pesquisa de Literatura Infantil e Juvenil e de Educação Literária (Gretel), da Universidade Autônoma de Barcelona (UAB), na Espanha.

6 Gretel é um grupo de pesquisa em literatura e educação literária dentro da Universitàt Autònoma de Barcelona e é coordenado pela Profa. Dra. Teresa Colomer. 


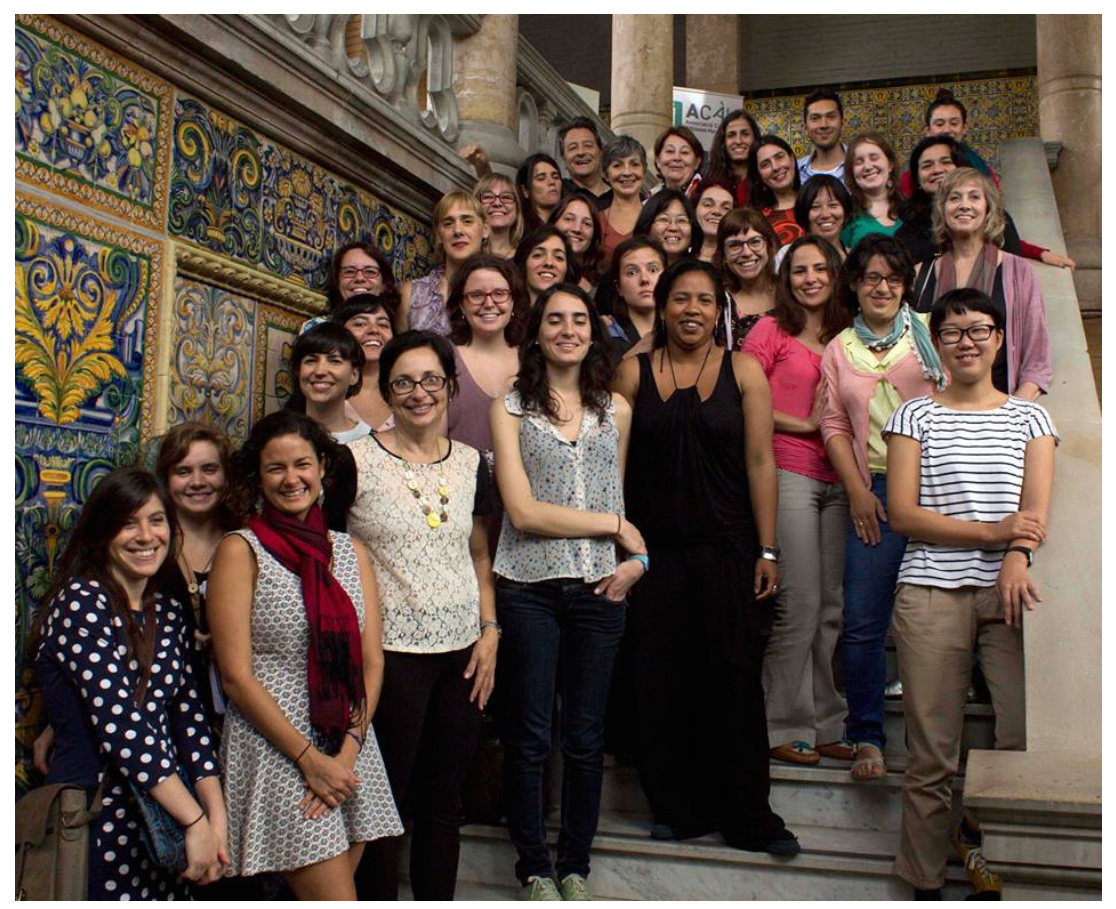

Fig. 1 - Alunos da $7^{\mathrm{a}}$ edición del Máster de Libros y Literatura Infantil y Juvenil de la Universitat Autònoma de Barcelona.

A Universitat Autònoma de Barcelona foi fundada em 1968 e está situada em Bellaterra, uma província de Barcelona, situada a $20 \mathrm{~km}$ da capital. Barcelona é um lugar incrível. É a capital da comunidade autônoma da Catalunha e a segunda maior cidade espanhola em número de habitantes. 


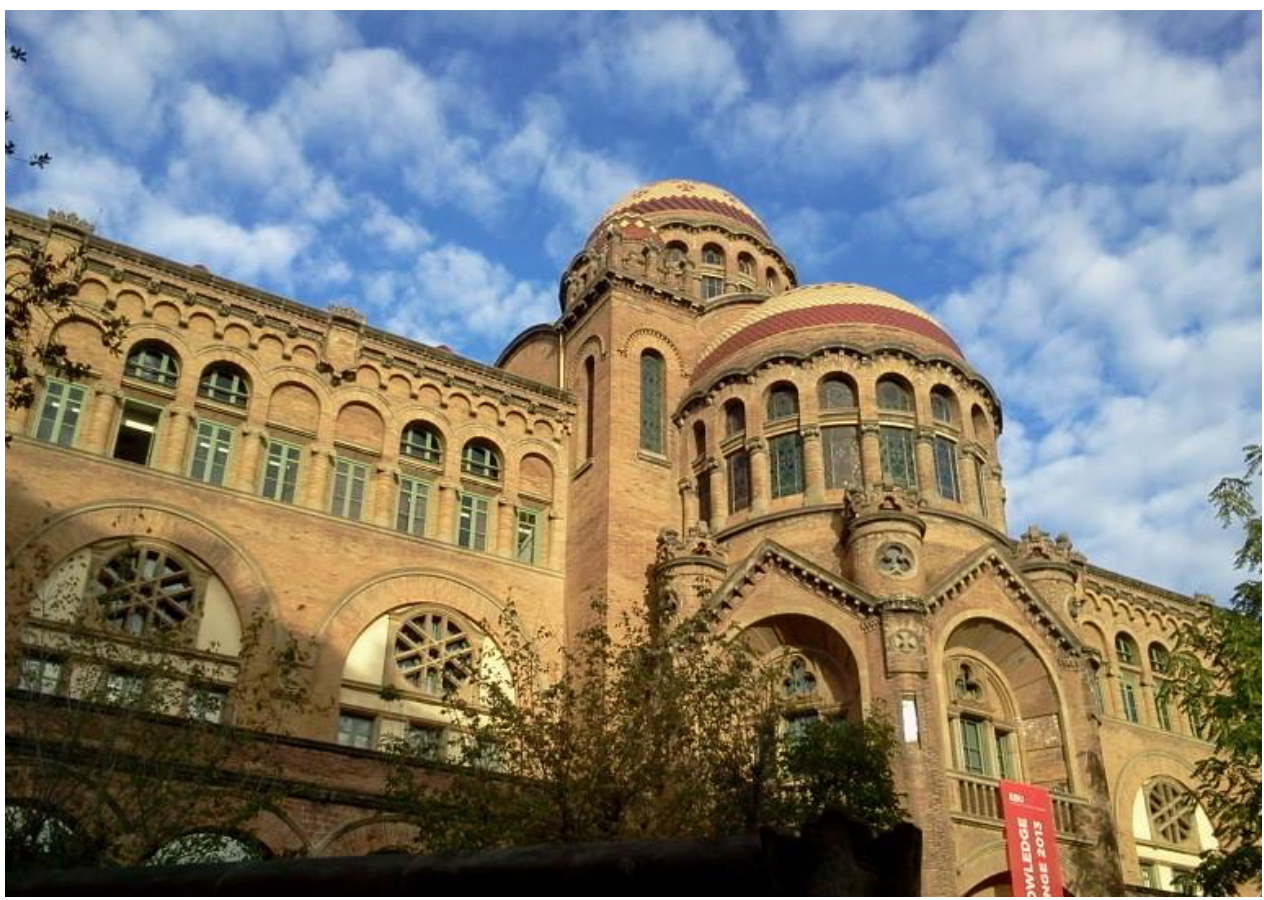

Fig. 2 - Foto da fachada da Universitat Autònoma de Barcelona, fundada em 1968. O campus fica em Bellaterra, situado a $20 \mathrm{~km}$ de Barcelona.

A primeira vez que visitei Barcelona foi em 2007 e foi amor à primeira vista. É um lugar único, com mar e serra, com altos e baixos, com cores e luzes únicas e com uma história que emociona. Por causa do Museo d'Historia de Catalunya, aprendi o básico da língua catalã, mas nunca tive coragem de falar com ninguém, nem da UAB.

É praticamente impossível visitar Barcelona e não se render a uma imersão cultural. Há alguns lugares que fascinam os visitantes que passam pela cidade, seja a turismo, a trabalho ou a estudos. A cultura de Barcelona pode ser dividida em: museus (Fundação Joan Miró, Museu Picasso, Museus Nacional da Catalunha etc.); arquitetura, com parada obrigatória nas obras de Gaudí, como o inacabado templo da Sagrada Família, o Parc Güell, a Casa Milà, também conhecida como La Pedrera e a Casa Batllò, mas sem esquecer a arquitetura do bairro gótico ou 
qualquer influência do modernismo catalão; esportes (sim, a cidade tem dois grandes clubes de futebol, o Espanyol e um dos mais populares e conhecidos do mundo, o F.C. Barcelona, além de dois estádios da elite da UEFA, um deles é o Estadi Olímpic Lluís Companys, que sediou as Olimpíadas de 1992); culinária (aqui entram os restaurantes e os bares, incluindo aqueles que fazem paellas e servem tapas).

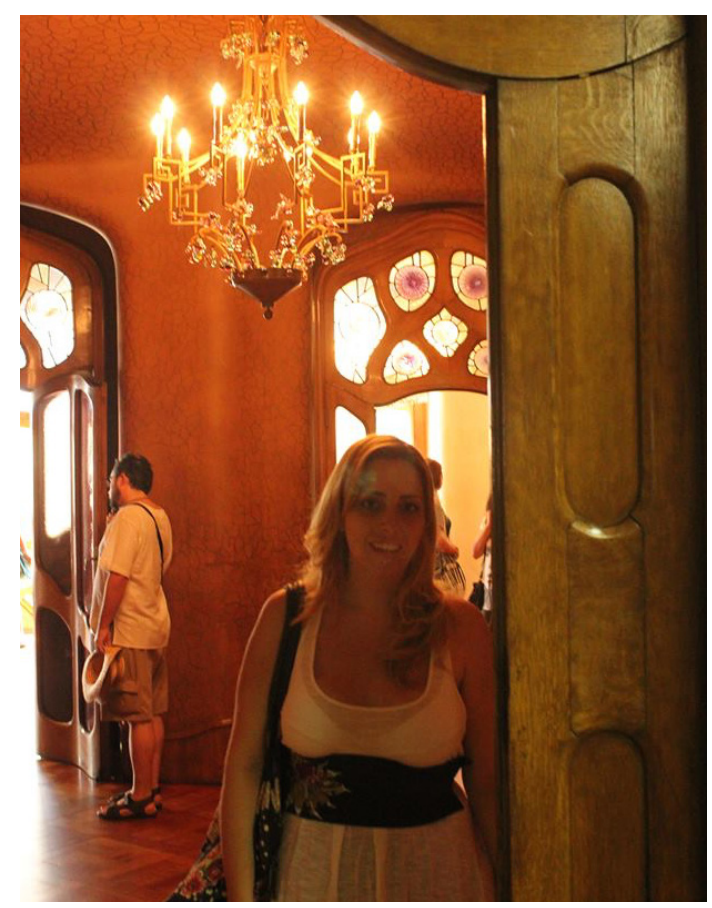

Fig. 3 - Eu, Camila, visitando a Casa Batllò, obra de Gaudí, em Barcelona.

Entretanto, para quem se propõe a estudar livros e literatura infantil e juvenil em Barcelona, é igualmente importante colocar na rota de visitas lugares como: a Casa Usher Llibreters, livraria com livros de temas variados, livros ilustrados e HQ; Casa Anita, a livraria mais famosa entre os alunos do Máster, linda e simpática, localizada no bairro Gràcia, que recebe pesquisadores e especialistas para bate-papo e faz contação de história e tem um catálogo para lá de especial; a Syndrome imagina- 
ria, especializada em livros interativos pop-ups; a Abracadabra, criada por Ricardo Rendón, um colombiano que vende livros infantis em oito idiomas - geralmente livros de editoras pequenas e independentes, uma excelente iniciativa, na minha opinião; a Al.lots, que tem boa reputação na Catalunha e, inclusive, edita livros infantis.

O fato é que, enquanto meus colegas fizeram esse trajeto de forma mais coletiva, minha trilha presencial se deu de forma mais individual. Isso acontece porque é na semana presencial que os laços são criados e, depois, cada um segue o seu próprio caminho de pesquisa.

Para entender um pouco mais como funciona o Máster de Libros y Literatura Infantil y Juvenil de la Universitat Autònoma de Barcelona, na semana presencial há diferentes cursos a que os alunos ingressantes assistem. Os alunos que não puderam comparecer ou que farão o curso no módulo on-line assistem à aula inaugural ao vivo e fazem outros tipos de atividade pelo Moodle.

Em seguida, todos os alunos têm que fazer o curso obrigatório de Introducción a la investigación en literatura infantil y juvenil, que faz um panorama geral sobre campos de investigação em LIJ. Neste curso cada um escolhe sua linha de pesquisa e, deste modo, seleciona três cursos básicos e dois cursos optativos, que devem ser escolhidos de modo a serem cursados de forma gradual e com o enfoque da pesquisa.

Como a linha de pesquisa que escolhi relacionava questões sociais e ilustrações nos livros infantis, dois temas tão diferentes, o contato que fiz com professores e colegas foi peculiar e, diferentemente do pessoal que conseguiu estabelecer um laço na semana inaugural presencial, a minha relação social com professores e colegas se deu de forma mais significativa on-line.

Aliás, o melhor do curso foi conhecer professores e colegas, sobretudo da América Latina e do Brasil, que não puderam fazer o curso presencial. Eles estavam em contato a todo momento, pois queriam aproveitar o tempo que tínhamos de discussão para conhecer as múltiplas realidades, referências, temas de pesquisas, objetivando usufruir o máximo do curso. 


\section{Problemas de CONEXÃo}

A primeira riqueza identificada no curso não foi o nome dos professores que me dariam aula; tão pouco o título que receberia ou a referência de ter feito um mestrado em Barcelona. Foi conhecer pessoas como: Analia Testa, argentina, jornalista e editora, que deixou a redação de um importante jornal para ser mediadora de leitura; a espanhola Inés Puig que deixou o mundo corporativo para dar aulas em um centro educativo; o professor mexicano Edgar Córdova, que queria trabalhar com literatura infantil para identidade mexicana etc.

Foi quando entendi que estava no meio de muitos conflitos: tinha colegas colombianas saídas de situações conflituosas de guerra que montavam bibliotecas e programas de incentivo à leituras; havia o problema, em diferentes países da América Latina, de identidade e alteridade, com um mercado editorial onde o (pre)domínio é de livros essencialmente espanhóis, com realidades madrilenas; haviam outros conflitos como o bilinguismo e multiculturalismos em regiões afastadas.

Ao escolher questões sociais como parte da minha pesquisa, percebi que teria de ressignificar muitas das questões de que trataria, para poder discutir o meu ponto de vista. As referências, mesmo dos livros infantis que discutíamos, eram distintas. Descobri que muitas das referências das crianças da América Latina não são de livros publicados em seu próprio país, mas obrigatoriamente editados e importados da Espanha.

As referências de livros que eu tinha, como Ana Maria Machado, Ruth Rocha ou mesmo Monteiro Lobato, não eram as mesmas do curso nem dos meus colegas. Até então, eles nunca tinham ouvido falar de Ziraldo. Alguns colegas brasileiros, inclusive, por falta de percepção, tentavam discutir o racismo de Lobato em um fórum de argentinos, uruguaios, chilenos e colombianos que não tinham ideia do que é o Sítio do Picapau Amarelo. Este foi o maior problema de conexão que tive: pedir, no fórum, que a pesquisadora, uma educadora brasileira, repensasse sua proposta de discussão, tendo em vista os conhecimen- 
tos prévios dos colegas a respeito de racismo, do autor, da realidade brasileira e da situação colocada. O Brasil teve que ficar um pouco de fora em algumas discussões e tive que aprender a discutir algumas questões sociais mais no âmbito universal do que no particular.

\section{UMA JORNADA INESPERADA}

Durante o Máster, o Brasil esteve presente na minha trajetória de três formas extraordinárias:

(1) No fato (que me surpreendeu) de haver professores brasileiros ministrando disciplina no curso. Neste caso, cursei Indústria Cultural e Mercado de Literatura Infantil e Juvenil, ministrada por Dolores Prades e com João Luis Ceccantini, Prof. Dr. da UNESP.

(2) Em algumas disciplinas, tive que discutir algumas questões no âmbito mais universal, deixando as particularidades e as referências sociais brasileiras de lado, porém, no que diz respeito à ilustração, consegui fazer o oposto: escolhi estudar o ilustrador brasiliense Roger Mello. Minha proposta de pesquisa foi aceita em janeiro de 2014 e fui tão feliz com a escolha, baseada em critérios estéticos, sociais e técnicos que, em março de 2016, Roger foi informado que venceu o Prêmio Hans Christian Andersen na categoria ilustração e tornou-se o primeiro ilustrador da América Latina a receber o prêmio.

(3) Conheci algumas alunas brasileiras com pesquisas e iniciativas incríveis, entre elas, Thais Caramico7 que, na época, residia na Inglaterra e mantinha o Garatujas Fantásticas. Atualmente, Thais vive em Berlim e criou o Estúdio Voador ${ }^{8}$. Ela, inclusive, publicou

7 Thais Caramico, é jornalista e especialista pela Universitat Autònoma de Barcelona. Especializou-se em temas culturais e no universo das crianças como repórter e redatora do suplemento infantil.

8 Estúdio criativo especializado em conteúdo para crianças, pais e educadores. Disponível em: http://www.estudiovoador.com/. Acesso em: 18 nov. 2016. 
uma parte da minha pesquisa de final de curso sobre um dos livros do Roger Mello no blog, com o título: Problemas sociais nos livros ilustrados de Roger Mello9. Neste artigo, falo do livro Carvoeirinhos, que faz uma denúncia social sobre trabalho infantil nas carvoarias.

\section{QUEBRANDO PARADIGMAS}

Teresa Colomer foi uma das professoras que fez com que a minha trajetória acadêmica na UAB valesse a pena. Ministrando a disciplina Valores sociales y libros para niños ${ }^{10}$, Colomer conseguiu mudar minha percepção, por exemplo, em relação às aulas à distância.

Na disciplina dada via Moodle, Teresa Colomer mostrou-me que, quando um professor possui domínio pedagógico, teórico, técnico e social, tanto do assunto como da ferramenta, é possível dar/ter aulas participativas. Ao todo, fiz 7 (sete) disciplinas, sem contar a do trabaIho final. A disciplina da Profa. Dra. Teresa Colomer foi a que mais demandou de mim como aluna e pesquisadora e foi a que eu mais aproveitei em termos de leitura, trocas, fóruns, esclarecimento de dúvidas e trabalho de pesquisa.

Na minha avaliação, isto se deu pelo planejamento e pela forma que Colomer conduziu a disciplina - ela estava sempre presente. Posso confirmar isso, pois tive outras disciplinas on-line, como, por exemplo a de llustración y libros para niños ${ }^{11}$, que se mostraram um fracasso como disciplina on-line. Questiono-me, inclusive, se o problema era a falta de conhecimento técnico, de integração das novas tecnologias às práticas de sala de aula ou de didática da professora.

Teresa Colomer também me fez pensar sobre a questão da relação entre a literatura infantil e a educação. Sempre quis separar a discus-

9 Artigo disponível em: http://www.estudiovoador.com/blog?tag=Carvoeirinhos. Acesso em: 18 nov. 2016.

10 Valores sociais e livros infantis (tradução nossa).

11 Ilustração e livros infantis (tradução nossa). 
são da literatura infantil enquanto arte da literatura infantil utilitária, ou seja, do uso que os educadores fazem da literatura em sala de aula. Mas Colomer apresentou um programa com diferentes formas de abordar a literatura infantil em sala de aula de forma não-utilitária, discutindo os limites da literatura segundo um consenso cultural e artístico, valores sociais e valores educativos; discutimos sobre os valores de cada época, sobre as mensagens e os paradigmas, fazendo-me lembrar das disciplinas optativas da minha graduação; sobre ideologia dos livros e como detectá-la, sobre os valores atuais.

Apesar de algumas das referências teóricas que adotei a partir desta experiência serem destoantes das linhas seguidas pelos principais grupos de pesquisa de literatura infantil e juvenil, acredito que é sempre bom termos uma multiplicidade de olhares para um mesmo objeto, afinal:

A literatura é um sistema vivo de obras, agindo umas sobre as outras e sobre os leitores e só vive na medida em que estes a vivem, decifrando-a, aceitando-a, deformando-a. A obra literária não é produto fixo unívoca ante qualquer público; nem este é passivo, homogêneo registrando uniformemente o seu efeito. (CANDIDO, 2008, p. 86).

Resumidamente, fazer o Máster em Libros e Literatura Infantil y Juvenil na Universitat Autònoma de Barcelona foi uma experiência única e um privilégio. Infelizmente, o diploma não vale como um mestrado e está em um processo demorado de verificação de equivalência junto ao Ministério da Educação do Brasil. Enquanto isso, decidi fazer mestrado em Linguística Aplicada, na Unicamp.

- "Aonde fica a saída?", Perguntou Alice ao gato que ria. - "Depende", respondeu ao gato. - "De quê?", replicou Alice; - "Depende de para onde você quer ir..." (Lewis Carroll, Alice no País das Maravilhas) 


\section{REFERÊNCIA BIBLIOGRÁFICA}

CANDIDO, Antonio. Literatura e Sociedade. Rio de Janeiro: Ouro sobre Azul, 2008. 